Sädhanā, Vol. 26, Part 5, October 2001, pp. 447-463. C Printed in India

\title{
Modelling, analysis, and acceleration of a printed circuit board fabrication process
}

\author{
K S AITHAL ${ }^{1}$, Y NARAHARI ${ }^{2}$ and E MANJUNATH ${ }^{1}$ \\ ${ }^{1}$ Central Manufacturing Technology Institute, Tumkur Road, Bangalore \\ 560022 , India \\ ${ }^{2}$ Department of Computer Science and Automation, Indian Institute of Science, \\ Bangalore 560 012, India \\ e-mail: hari@csa.iisc.ernet.in
}

MS received 9 March 2000; revised 30 October 2000

\begin{abstract}
Product design and fabrication constitute an important business activity in any manufacturing firm. Designing an optimized product fabrication process is an important problem in itself and is of significant practical and research interest. In this paper, we look into a printed circuit board (PCB) fabrication process and investigate ways in which the fabrication cycle time can be minimized. Single class queueing networks constitute the modelling framework for our study. The model developed in this paper and the analysis experiments carried out are based on extensive data collected on a PCB fabrication company located in Bangalore, India. This is a representative PCB fabrication company involving multiple, concurrent fabrication works with contention for human/technical resources. Our model seeks to capture faithfully the flow of the fabrication process in this company and such other organisations, using queueing networks. Using the model developed, we explore how the cycle times can be reduced using input control, load balancing, and variability reduction. The model presented is sufficiently generic and conceptual; its scope extends beyond that of a PCB fabrication organization.
\end{abstract}

Keywords. Queueing; manufacturing; modelling; cycle times.

\section{Introduction}

While manufacturing firms have been developing new products since the industrial revolution, the importance of designing and developing high quality new products has increased dramatically in recent years. The main forces driving the importance of product design and development are competition - internal and external to the company, changing customer needs, and changes in technology. These driving forces have created a competitive imperative for speed, efficiency, and high quality in the design and development process. This creates substantial pressure on engineering teams to develop better products and at the same time to develop them faster. It is also observed from various studies (Hopp 
et al 1990; Milson et al 1992) that product life cycles are continuously becoming shorter, which has forced companies to reduce the product design and development lead time. At the same time, the effects of shorter lead times can be considered beneficial only if they can be achieved without undue sacrifices in other areas such as quality. Recent literature on lead time modelling of product design and development has revealed many techniques for faster development of new products (Millson et al 1992). These techniques are based on some generic approaches, which focus on the reduction of lead time. Companies follow one or a combination of these approaches to accelerate the product design and development cycle. However, these approaches can be applied only when the entire process is clearly understood, which is achieved through faithful modelling of the process.

Our objective in this paper is to model and analyse a typical industrial fabrication process and to investigate the methods to reduce fabrication cycle time. We specifically consider the PCB fabrication process. We apply queueing theory to model this process, and, using the model developed, we explore the improvement in fabrication cycle time using input control, load balancing, and variability control.

\subsection{Review of relevant work}

Considerable amount of research has been carried out in the past decade in the important areas of lead time modelling and lead time reduction in a manufacturing firm. For example, Hopp et al (1990) in their paper have explored the causes of excessive lead time and suggest practical, inexpensive strategies for reducing lead time. Their suggestions are based on a detailed study of six manufacturing companies and a survey of literature in the related area. Hopp \& Spearman (1996) have listed several techniques (based on queueing principles) for compressing manufacturing lead times. Some of the techniques for lead-time reduction discussed by them, such as variability reduction, have been explored in our work in the current paper. Quick response manufacturing (QRM), presented by Suri et al (1995) and Suri (1998) is an important collection of techniques to compress process lead times in manufacturing firms. QRM principles include intelligent scheduling of bottleneck resources, product-oriented cellular organization, use of a judicious mix of push and pull control policies etc. It is argued that substantial improvement in lead time, of the order of $75 \%$, in new product introduction, and $90 \%$ to fill orders for existing products can be achieved by using QRM techniques. Apart from reductions in lead times, when properly implemented, a QRM strategy also results in quality improvement and cost reductions.

Lead time reduction techniques have been popular in the context of the product design process and in new product development processes also. Millson et al (1992) present a survey of major approaches for accelerating new product development. They suggest a general set of techniques for reducing the development cycle time of new products, and classify these techniques into five basic categories. These are: (a) Simplify the process; (b) eliminate the delays; (c) eliminate steps; (d) speed up operations; and (e) make processes parallel. There are several books that have appeared in recent years, which focus on improving the product development process. In their book, Clark \& Wheelwright (1993) discuss lead time reduction in a qualitative way with illustrative case studies. Krishnan et al (1995) in their study, have discussed a method of reducing product development lead time by overlapping development activities through the exchange of preliminary design information. In their approach, downstream development activities begin with 
unfinalized upstream design information, and new design changes are incorporated in the subsequent iteration of development. Adler et al $(1995,1996)$ have analysed product development lead time in organizations that involve multiple, concurrent, non-unique projects, with shared resources, using single-class queueing network models. In fact, many of the techniques explored by us in the current paper, such as input control, process control, and load balancing, are suggested by these two papers. More recently, Narahari et al (1999) in their study have come up with lead-time models of product design and development processes using both single-class and multi-class queueing network models, and explored lead-time reduction using various lead-time reduction techniques. These techniques (Narahari et al 1999) have also inspired the current-work. Similar modelling and optimizing techniques are investigated for software product development by Nagaraju (1997).

Process models offer a systematic, well defined way of representing the structure of process. They record activities that are performed in the process with the inter-dependencies among activities. Lyons et al (1995), in their report, have explained key requirements, industry practices, and research questions that should drive new methods and computer tools for process modeling of the product realization.

\subsection{Queueing networks}

A queueing network is a collection of stations (or service facilities) arranged in such a way that the customers proceed from one station to another in order to fulfill their service requirements. Each station has an associated queue in which jobs may wait prior to receiving service. The stations are characterized by service rate and the queueing discipline. The service rate is the number of jobs departing from the station per unit time, and queueing discipline is the order in which arriving jobs receive service. A queueing network is said to be Open Queueing Network (OQN), if customers are permitted to enter or leave, whereas a network is said to be Closed Queueing Network (CQN), if the number of customers in the network remain same at all times. A queueing network may contain several classes of customers. Customers of a particular class have identical service requirement.

Queueing networks have been widely used in the modeling of manufacturing and production processes (Viswanadham \& Narahari 1992; Hopp \& Spearman 1996). A workpiece or a job in a factory floor goes through a sequence of operations in multiple machine centres, waiting in multiple queues during its journey in the production process. Queueing networks can capture very accurately the flow of jobs, contention for resources, and the waiting periods. Using these models, the manufacturing lead time can be computed and lead time reduction strategies can be experimented with. This motivates the use of queueing networks to model the flow of PCB jobs in a PCB fabrication facility.

\subsection{Analysis tools}

Two software packages are used to analyses the performance measures of PCB fabrication process considered. These software packages have been developed at the Department of Computer Science and Automation, Indian Institute of Science, Bangalore. 
1.3a Open queueing network analyser: This tool analyses open Jackson queueing networks with multiserver stations (Viswanadham \& Narahari 1992). The inputs to the package are (Kiran Kumar 1995):

- Number of stations in the network;

- number of servers at each station;

- external arrival rate of jobs at each station;

- service rate of each station;

- routing probabilities;

- squared coefficient variation (SCV) of arrival rate;

- SCV of service rate of each station.

The tool evaluates the utilization of each station, visit counts, waiting time, and number of jobs at each station, and total number of jobs and total wait time of the network.

$1.3 b$ Closed queueing network analyser: This tool uses the mean value analysis to evaluate the performance measures of the CQN. The input to the packages are (Kiran Kumar 1995):

- Number of stations in the network;

- number of jobs in the network;

- service rate of each station;

- routing probabilities.

The tool evaluates visit counts at each station, queue length, waiting time at each station and total waiting time of the network.

\subsection{Outline of the paper}

In $\S 2$ of this paper, we describe the PCB fabrication process as seen in our representative company, which we call as PCB-FAB. In $\S 3$, we present a model of this PCB fabrication process based on single class open queueing networks. In $\S 4$, we analyses the model developed, using software tools. With these analytical tools, we investigate the variation of the mean cycle time and the variance of cycle time with input rate, squared coefficient variation of interarrival time and the mean number of customers in the system. In $\$ 5$, we present the practical implications of our study.

\section{PCB fabrication process: An outline}

Printed circuit boards are found virtually in all electronic equipments. They are also the most custom-designed part of any electronic equipment. PCBs provide mechanical support apart from functional electrical interconnection between components. A PCB is a dielectric substrate with metallic circuitry photo-chemically formed upon that substrate. Typically, there are two major types of board materials (dielectric substrates) that are used for the baseboard, fiberglass (glass-epoxy) and phenolic paper. The baseboard is also known as copper clad. There are three types of printed circuit boards available today. They are

(i) Single sided boards: Where the entire circuit is laid on one side of the board and there may or may not be holes on the board for mounting of components, or for interconnection of components. 
(ii) Double sided boards: With the circuit on both sides of the board and electrical connection is established by drilling holes through the board and plating copper through the holes.

(iii) Multilayer boards: Two or more pieces of dielectric materials with circuitry formed upon them and are stacked up and bonded together. Electrical connections are established from one side to the other, and to the inner layer circuitry by drilled holes which are subsequently plated through with copper.

Printed circuit technology may be divided into three basic phases or stages: Engineering, photography and fabrication. The circuit diagram in the form of a schematic diagram is photo-plotted on a film which is one of the inputs for the fabrication process. The following paragraphs briefly describe the stages involved in the PCB fabrication process. Figure 1 shows the various stages in the PCB fabrication process.

\subsection{Photo film inspection}

The following documentations required for the fabrication process are collected from the customer, along with the sales order: schematic drawings, manufacturing specifications, circuit films, drilling details, and $\mathrm{CNC}$ drill data etc. Once these documentations are reviewed for their correctness, then contact films are developed from the circuit films. These contact films are used in fabrication process. If the documents are not suitable for fabrication, it is returned back to the customer.

\subsection{Panel cutting}

Copper clads with thin layer of copper on both sides are used for fabrication of double sided PCB. The standard thickness of copper layer is 18 and $35 \mathrm{~mm}$. This copper clad is cut into pieces. These pieces of copper clad are called as panels. Depending on the size of PCBs to be fabricated, a panel accommodate one or more than one PCB. Cutting these panels to the PCBs of the required size is done at the trimming stage of the process. On all the four sides of the panel, extra space is left which is required to hold the panel during different stages of fabrication process, without affecting the PCB area.

\subsection{Drilling holes}

Once the panel is cut, the next stage is the drilling of holes. Either CNC drilling or manual drilling is used for this purpose. It is observed from past data that $98.92 \%$ of the jobs are drilled on CNC drilling machine and only $1.08 \%$ of the jobs are drilled on optical drilling (manual). Manual drilling is only used in one or more of the following situations: (1) very low order quantities, (2) non-availability of drill data, and (3) number of holes on the PCB is too low for using the CNC drilling machine. The panels are pinned together in stacks from one to four high, depending on panel thickness. These are loaded onto the drilling machine. NC part program is loaded into the CNC drilling machine and all required holes are drilled at proper locations, with correct drill size. Latest CNC drilling machines are equipped with automatic tool changer which will automatically change drill bits when the hole size changes. Some CNC drilling machines are also equipped with multiple spindle, so that simultaneously multiple stacks of panels can be drilled. Once all the holes are drilled, the panel is cleaned and deburred. 

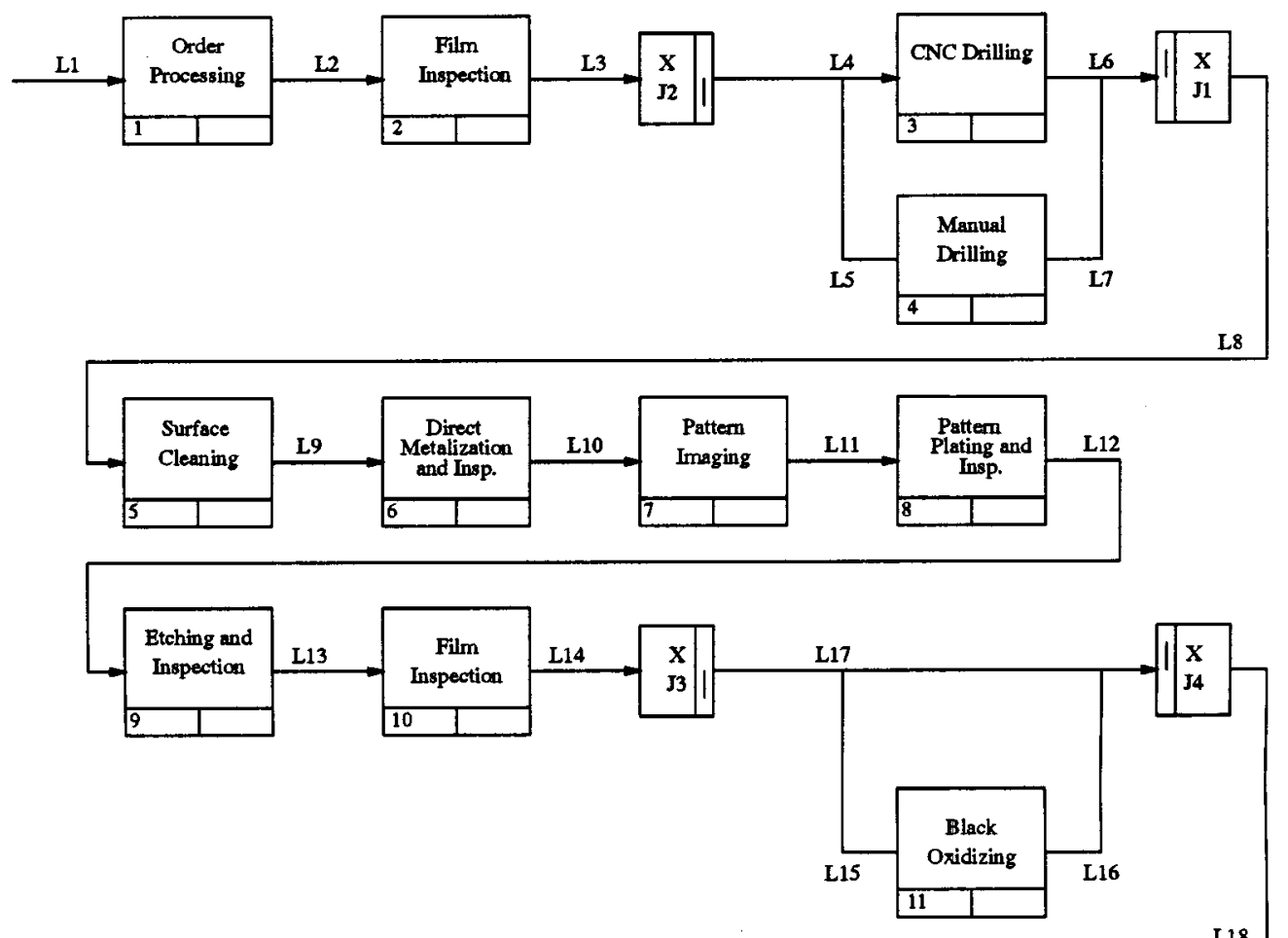

L18

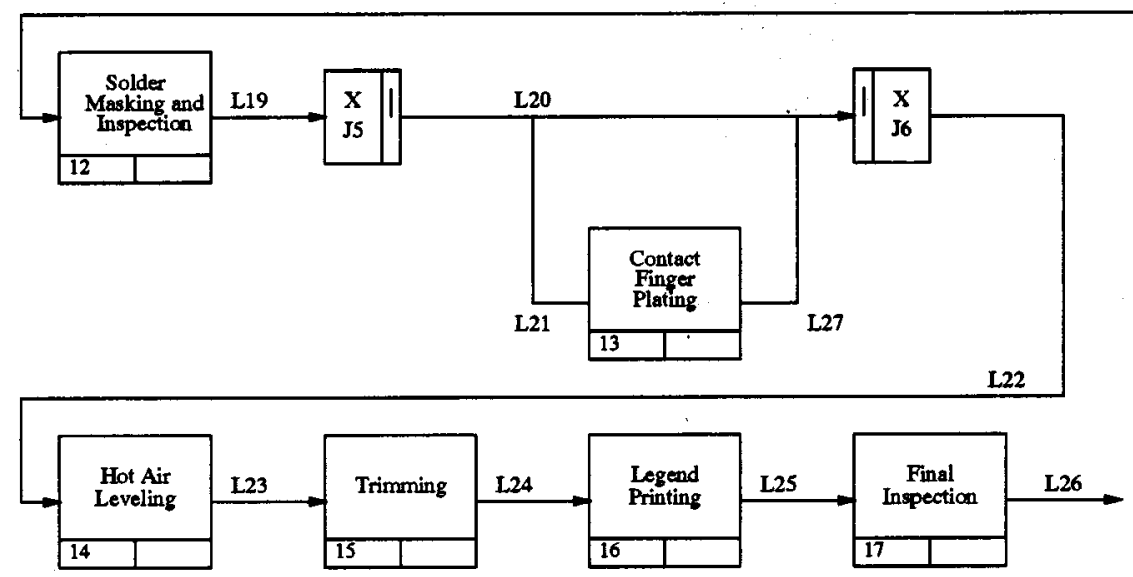

Figure 1. Various steps in the PCB fabrication process.

\subsection{Electro-less copper plating}

Once the panel is deburred and inspected, then it goes to the next stage, that is, electro-less copper plating. The sole purpose of electro-less copper plating is to metallize the wall of drilled holes. This hole metallization (1) provides an electrical connection between the two sides of the board, and (2) serves as a metal substrate upon which subsequent copper may be deposited electrolytically. This connectivity is done by peridium coating 
on the inner side of holes by passing each panel through a series of electrolyte baths. After this is done the panel is cleaned and dried.

\subsection{Pattern imaging}

After the holes have been plated, the circuit pattern is imaged on to each of the panels. The image defines the circuit for plating and etching purposes. Negative circuit film is used for this purpose. Both sides of the panel are coated with a thin layer of dry film photo resist. The circuit film is laid on one side of the drilled panel and exposed to ultraviolet light. Except the circuit area, all the other area on the panel is polymerized and hence becomes hard. This is repeated for the other side. The unexposed photo resist is washed away during development, to leave the circuit pattern. This process is carried out for each panel.

\subsection{Pattern plating}

In this stage of the fabrication process, the thickness of copper tracks on the panel is increased by $20-30 \mathrm{~mm}$. Over the copper tracks, tin-lead plating is done, which (1) protects the conductive copper from oxidation thereby preserving solderability, and (2) acts as etch resist for the subsequent etching stage to follow.

\subsection{Etching and tin-stripping}

Once the pattern plating is done, the dry film photo resist is stripped by a solvent. This bares the unwanted copper foil which is etched away to leave the plated circuit. Copper foil is etched by spraying the etchant to both sides of the panel as it moves on a conveyor.

\subsection{Solder masking}

Solder mask is an epoxy barrier applied to one or more sides of the panels. It prevents solder bridges from forming during the wave soldering operation performed by the board user. It also reduces the ability of molten solder to adhere to the board's surface, and acts as a barrier which prevents damage to the circuitry due to scratches. The solder mask is typically applied by screen printing using solder mask film which enables the entire board surface to be covered, except for the holes, pads and contact fingers.

\subsection{Contact finger plating}

Contact finger plating is the next operation (optional) in the fabrication of PCBs. Contact fingers are the rows of tabs along one or more edges of the boards. These tabs fit into connectors in the electronic equipment in which the PCB is used. They must be durable and resistant to tarnishing and oxidation. Over the bare copper tracks, plating is done first with nickel, then with gold. Nickel serves as a wear-resistant barrier between the copper and gold and gold is used on the top because of its excellent conductivity and resistance to oxidation. 


\subsection{Hot air leveling}

During this stage of the fabrication process, the panels are dipped in solder bath, so that all PTHs and solder points are covered with tin-lead plating. These panels are passed through a conveyor, while hot air is blown from one side of the panel, so that all the tin-lead covered holes are cleared.

\subsection{Trimming}

During this stage of the process, the panels are cut to the required size of individual PCB. Printed circuit boards contain holes which are plated through and some which are not to have any plating in them at all. Since the electro-less copper process will deposit copper inside drilled holes, a second drilling step is needed. These holes are mainly used for mounting the components and fixing the connectors etc.

\subsection{Legend printing}

The legend or nomenclature, is screen-printed onto PCBs to identify the components, for assembling and testing purposes. This screen-printing operation is performed using legend print film supplied by the customer. Since legend is permanent, once it is dried, legend-printed panels must also be checked for legibility and completeness of the printed image.

\subsection{Inspection}

Inspection is done at various stages of the fabrication process. If the panel is accepted at that stage, it is passed on to the next stage. Otherwise it goes back to rework, to the same stage of operation. In some cases, when the panel is beyond rework, it is rejected.

\section{A queueing network model of PCB fabrication}

Figures 2 and 3 show the two parts of a queueing network model of the printed circuit board fabrication process. The description of service rendered to the job at each stage of the process is explained in $\S 2$.

A new job enters the system at station number 1, that is, O.Proc (order processing) and successfully completed jobs exit the system from station Del. (delivery of PCBs). Each job undergoes a sequence of operations in the manner shown in figures $2 \& 3$. For example, after successfully finishing processing at P.cut (station 3), a job is routed to either a CNC drilling station (with probability 0.9892) or a manual drilling station (with probability 0.0108 ). These probabilities are chosen based on past data available (which showed that $98.92 \%$ of the jobs underwent CNC drilling). A job can visit a station several times due to rework. The probability of returning to the previous stage after completing service at a particular station is shown for all appropriate feedback possibilities. For example, after inspection at station number 11, a job will come back to station number 10 (Copper and Tin Plating) for rework and the probability of this feedback is 0.155 . This means that with a probability of 0.845 , the job will go to the 


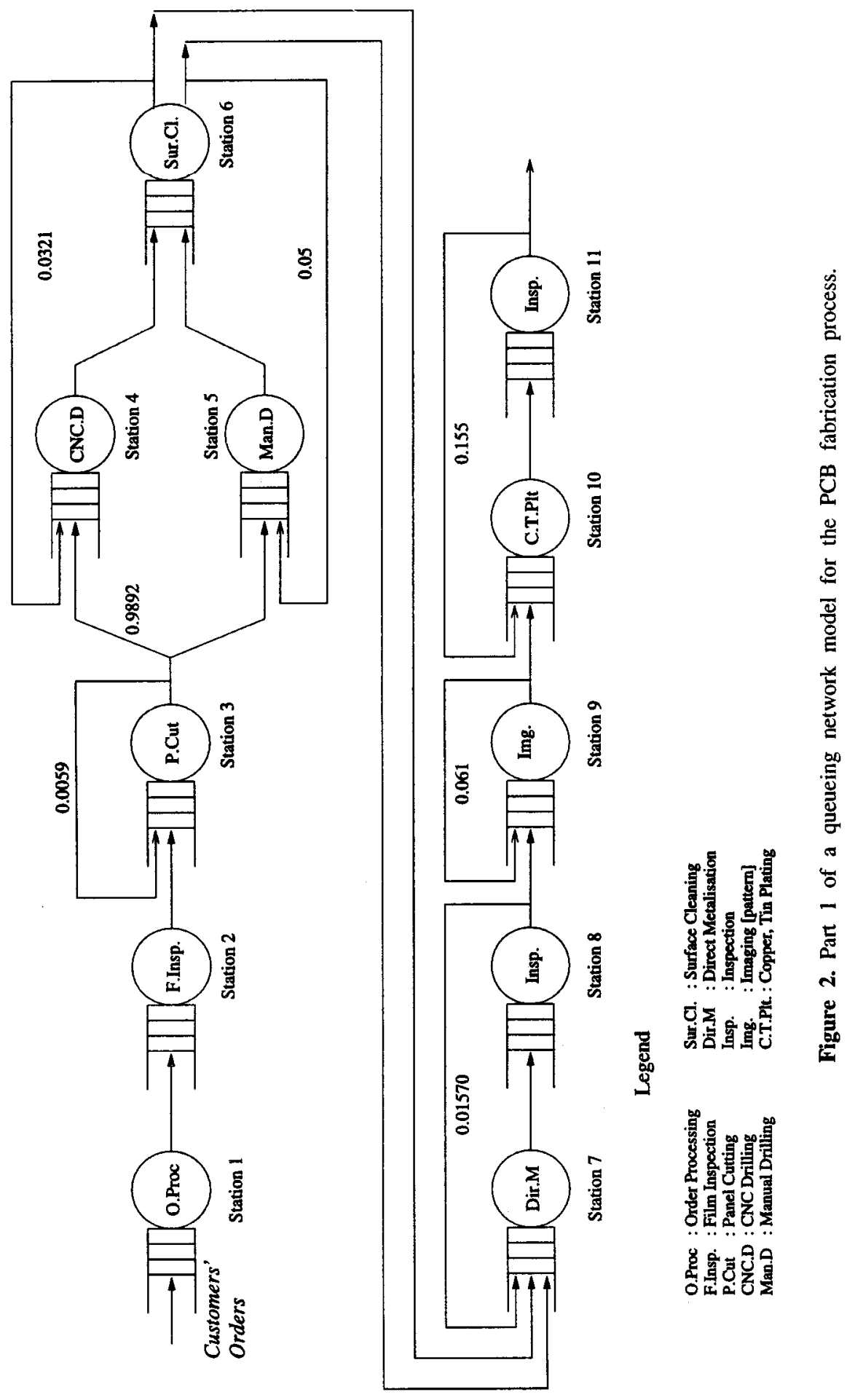




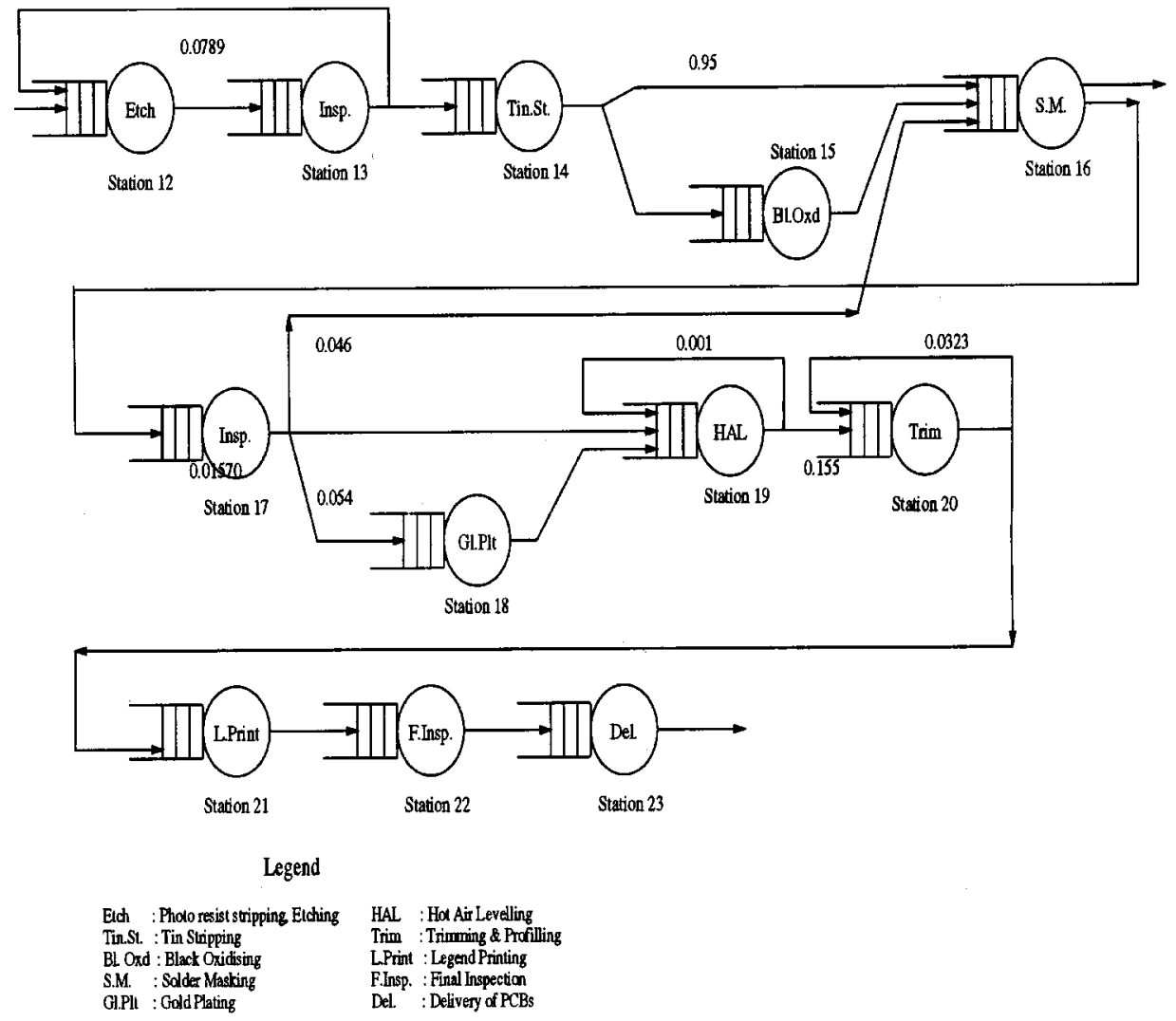

Figure 3. Part 2 of a queueing network model for the PCB fabrication process.

next stage, that is, etching. These feedbacks are represented by backward arrows in the figure, while the forward arrows indicate that the process is successfully completed at that station. The number near the feedback arrows indicates the probability of failure at that station, and hence the probability of rework. Since most of the stages of fabrication process involve chemical action, we have made the reasonable assumption that the service time distribution at a station for a job visiting the station for the first time is the same as that of the fed-back jobs. The routing probability is independent of the previous history of the job.

We have obtained the data pertaining to inter-arrival time between successive new jobs, the service times at various stations, the feedback probabilities either by interviewing the company personnel or from their record book. For our experiment we have considered the fabrication of PCBs with a batch size of 100. In this PCB-FAB, most of the processing stages do batch processing with a batch size of 100 . That is, there is a setup time for each batch and then 100 PCBs are processed (either sequentially or in smaller batches) until 100 PCBs are processed and then there is a new setup for the next batch of 100 PCBs. The processing time at each stage, therefore, corresponds to a single setup time (for the entire batch of 100) plus the total execution time for 100 PCBs. The mean service rate at each station is calculated according to the data we obtained from the company and are shown in table 1 . We have considered the unit of time as one day. 
Table 1. Service rates at different stations for the base model of PCB fabrication process.

\begin{tabular}{|c|c|c|c|c|c|}
\hline $\begin{array}{l}\text { S. } \\
\text { No. }\end{array}$ & Station name & $\begin{array}{r}\text { Working } \\
\text { hours/day }\end{array}$ & $\begin{array}{l}\text { Mean service } \\
\text { time (min) }\end{array}$ & $\begin{array}{l}\text { Mean service } \\
\text { time (days) }\end{array}$ & Service rate \\
\hline 1 & Order processing & 8.0 & 120 & 0.2500 & 4.0000 \\
\hline 2 & Film inspection & 8.0 & 35 & 0.0729 & 13.7143 \\
\hline 3 & Panel cutting & 8.0 & 50 & 0.1042 & 9.6000 \\
\hline 4 & CNC cutting & 24.0 & 500 & 0.3472 & 2.8800 \\
\hline 5 & Manual drilling & 24.0 & 1080 & 0.7500 & 1.3333 \\
\hline 6 & Surface cleaning & 24.0 & 200 & 0.1389 & 7.2000 \\
\hline 7 & Direct metallization & 24.0 & 120 & 0.0833 & 12.0000 \\
\hline 8 & Inspection & 8.0 & 100 & 0.2083 & 4.8000 \\
\hline 9 & Imaging & 24.0 & 350 & 0.2431 & 4.1143 \\
\hline 10 & Copper and tin plating & 24.0 & 300 & 0.2083 & 4.8000 \\
\hline 11 & Inspection & 8.0 & 100 & 0.2083 & 4.8000 \\
\hline 12 & Etching & 24.0 & 400 & 0.2778 & 3.6000 \\
\hline 13 & Inspection & 8.0 & 100 & 0.2083 & 4.8000 \\
\hline 14 & Tin stripping & 24.0 & 300 & 0.2083 & 4.8000 \\
\hline 15 & Black oxidising & 24.0 & 120 & 0.0833 & 12.0000 \\
\hline 16 & Solder masking & 24.0 & 235 & 0.1632 & 6.1277 \\
\hline 17 & Inspection & 8.0 & 120 & 0.2500 & 4.0000 \\
\hline 18 & Gold plating & 24.0 & 240 & 0.1667 & 6.0000 \\
\hline 19 & Hot air levelling & 24.0 & 200 & 0.1389 & 7.2000 \\
\hline 20 & Trimming & 24.0 & 200 & 0.1389 & 7.2000 \\
\hline 21 & Legend printing & 24.0 & 100 & 0.0694 & 14,4000 \\
\hline 22 & Final inspection & 8.0 & 15 & 0.0313 & 32.0000 \\
\hline
\end{tabular}

The mean service times tabulated in table 1 above are considered, for a batch size of 100 double-sided PCB fabrication, with two PCBs per panel, and 2000-2500 holes each.

The QN model is thus described by the following parameters: Number of nodes, mean and variance of inter-arrival time between successive new jobs, mean and variance of service time distribution at each station, routing matrix, and the scheduling policy to be followed at each station. We assume that a non-preemptive FCFS policy is followed at each station. We also assume that the buffers at all the stations have infinite capacity.

\section{Fabrication cycle time reduction}

The main purpose of our study is to evaluate the performance of the model of figures 2 and 3, and explore several opportunities for cycle time reduction, as cycle time is the most important performance measure. Other performance measures such as mean number of jobs in progress, utilization of resources can also be computed. Since the model is a single class open-queueing network with single-server station, Markovian routing, general inter-arrival times, and general service times, we have used the software package developed at the Indian Institute of Science (Kiran Kumar 1995). The performance measures are computed using analytical formulae.

Based on the data collected at the company PCB-FAB, we first created a base model for which we chose inter-arrival time of 2 jobs/day. With this data, the base model gives a mean cycle time of 7.075 days, if the service times are assumed to be exponentially distributed with mean service time as in table 1. Table 2 shows the variations of mean cycle time for different inter arrival times (IATs). Cycle time increases nonlinearly with 
Table 2. Mean cycle time for various input arrival processes.

\begin{tabular}{lrrr}
\hline & \multicolumn{3}{c}{ Mean cycle time in days } \\
\cline { 2 - 4 } $\begin{array}{l}\text { Mean IAT (days) } \\
\text { for batch of 100 }\end{array}$ & Poisson arrivals & Uniform arrivals & $\begin{array}{c}\text { Deterministic } \\
\text { arrivals }\end{array}$ \\
\hline 0.901 & 4.838152 & 4.344657 & 4.282018 \\
0.571 & 6.211016 & 5.606141 & 5.521283 \\
0.500 & 7.075244 & 6.420974 & 6.326138 \\
0.466 & 7.761732 & 7.058958 & 6.955073 \\
0.417 & 9.612223 & 8.732203 & 8.597173 \\
0.391 & 12.061462 & 10.864682 & 10.675641 \\
0.376 & 15.805556 & 14.025449 & 13.737866 \\
0.367 & 22.378527 & 19.469528 & 18.991804 \\
0.363 & 34.725552 & 29.608326 & 28.758997 \\
0.360 & 61.668919 & 51.664593 & 49.993061 \\
0.359 & 119.294205 & 98.794846 & 95.357758 \\
0.358 & 253.370178 & 208.427353 & 200.878296 \\
0.3578 & 485.777588 & 398.455322 & 383.776978 \\
\hline
\end{tabular}

the input arrival rate. This is because of the congestion of many jobs at bottleneck stations like CNC drilling and etching.

\subsection{Cycle time reduction through input control}

Since waiting times are positively correlated with the fluctuation in the arrival of incoming jobs, deterministic arrivals provide better cycle time. Table 2 shows the effect of input control on mean cycle time. The first column corresponds to the mean inter-arrival time for a batch of 100 PCBs, measured in days. In our base model, we have considered Poisson arrival distribution (where SCV of arrival is 1.0). The table shows that, if we reduce the fluctuation in arrival process, we can achieve a reduction in cycle time. We reduced the SCV of arrival rate from 1.0 (exponential arrival rate) to 0.144 (uniform arrival rate) to 0 (deterministic arrival rate). As the inter-arrival times become less variable, there is found to be considerable reduction in mean cycle times. The practical implication of this is that the PCB-FAB manager ought to schedule the arrival of raw materials and other items required to start fabrication in a careful way, so as to arrive as "deterministically" as possible. This in turn calls for effective communication and co-ordination with all vendors who supply the items that are required by the PCB-FAB.

The second method of reducing mean cycle time by controlling fluctuation in arrival of jobs is by allowing new job to enter the system only when a job in the system comes out of the system after finishing its entire processing. This ensures a constant population of jobs in the system. This type of system is modelled as a closed queueing network $(\mathrm{CQN})$. The CQN improves the cycle time performance by eliminating the variability due to uncontrolled arrivals of job which are responsible for poor performance of OQN. Table 3 shows the effect of operating the system in fixed population mode. The routing probabilities are as in figure 1 and the mean service times are as in table 1 . The first column gives the current population of the network in CQN mode; the second column gives the corresponding mean cycle time; the third column gives the mean inter-arrival time that is consequent on having the corresponding population in the closed network; the fourth column provides the corresponding throughput rate of jobs completed per day; 
Table 3. Cycle time reduction through input control.

\begin{tabular}{lcccc}
\hline $\begin{array}{l}\text { Population } \\
\text { for closed } \\
\text { model }\end{array}$ & $\begin{array}{c}\text { Mean } \\
\text { cycle time } \\
\text { (days) }\end{array}$ & $\begin{array}{c}\text { Associated } \\
\text { mean IAT } \\
\text { (days) }\end{array}$ & $\begin{array}{c}\text { Throughput } \\
\text { rate } \\
\text { (per day) }\end{array}$ & $\begin{array}{c}\text { Mean cycle time } \\
\text { for open models } \\
\text { (days) }\end{array}$ \\
\hline 5 & 4.504 & 0.901 & 1.110 & 4.838 \\
10 & 5.710 & 0.571 & 1.751 & 6.211 \\
13 & 6.469 & 0.500 & 2.0 & 7.075 \\
15 & 6.990 & 0.466 & 2.146 & 7.762 \\
20 & 8.343 & 0.417 & 2.397 & 9.612 \\
25 & 9.772 & 0.391 & 2.558 & 12.061 \\
30 & 11.279 & 0.376 & 2.660 & 15.806 \\
35 & 11.286 & 0.367 & 2.722 & 22.379 \\
40 & 14.507 & 0.363 & 2.757 & 34.726 \\
45 & 16.206 & 0.360 & 2.777 & 61.669 \\
50 & 17.941 & 0.359 & 2.787 & 119.294 \\
55 & 19.700 & 0.358 & 2.792 & 253.370 \\
60 & 21.473 & 0.3578 & 2.794 & 485.778 \\
\hline
\end{tabular}

and the fifth column gives the mean cycle time of the same network operated in the open queueing network mode, to get the same throughput. From the table it is clear that the mean cycle time is reduced drastically if one operates the system in closed mode to get the same throughput. For example, for the population of 30, the mean cycle time is 11.279 days which corresponds to the throughput rate of 2.66 jobs/day. To achieve the same throughput rate in the open queueing network requires 15.806 days.

Note that the fixed population inside the network includes jobs that need reworking. The implication of having to maintain a fixed number of jobs inside the network is that we should schedule arrivals of raw materials for a new job to synchronise with the completion of processing of a job in the network. This again calls for smart co-ordination with vendors and intelligent order management.

\subsection{Cycle time reduction through process control}

We have seen in $\$ 4.1$ above, that the mean cycle time can be reduced by controlling the variation in arrival rate of new jobs. Hence, the next logical move to reduce the mean cycle time is to control the variation in service time of individual station. This we call as process control. Table 4 shows effect of process control on mean cycle time. First three columns of the table show mean cycle time and mean number of jobs currently being serviced in the system, for various inter-arrival rates. It is assumed that arrival rate and service rates are exponential. The mean service time is taken from table 1 and the routing probabilities are as shown in figure 1. The next two columns correspond to mean cycle time and mean number of jobs for the same system, but with uniform distribution of service time. That is, the mean service time as shown in table 1, with SCV of 0.144. The last two columns give the mean cycle time and mean number of jobs currently being serviced for the same system, but with deterministic distribution of service times.

It is very clearly seen from the table that the reduction in mean cycle time can be achieved by controlling variation in service time, which implies controlling the process involved in the service station. This calls for effective use of best practice techniques such as statistical process control and such other variability reduction techniques. 
Table 4. Mean cycle time with different service time variabilities.

\begin{tabular}{|c|c|c|c|c|c|c|}
\hline \multicolumn{3}{|c|}{ Exponential service times } & \multicolumn{2}{|c|}{ Uniform service times } & \multicolumn{2}{|c|}{ Deterministic service times } \\
\hline $\begin{array}{l}\text { IAT } \\
\text { (days) }\end{array}$ & $\begin{array}{c}\text { Mean } \\
\text { cycle time }\end{array}$ & $\begin{array}{c}\text { Mean } \\
\text { nos. of } \\
\text { jobs }\end{array}$ & $\begin{array}{c}\text { Mean } \\
\text { cycle time }\end{array}$ & $\begin{array}{c}\text { Mean } \\
\text { nos. of } \\
\text { jobs }\end{array}$ & $\begin{array}{l}\text { Mean } \\
\text { cycle time }\end{array}$ & $\begin{array}{c}\text { Mean } \\
\text { nos. of } \\
\text { jobs }\end{array}$ \\
\hline 0.901 & 4.838 & 5.370 & 4.166 & 4.624 & 4.068 & 4.515 \\
\hline 0.571 & 6.211 & 10.875 & 4.570 & 8.002 & 4.322 & 7.568 \\
\hline 0.500 & 7.075 & 14.150 & 4.799 & 9.599 & 4.452 & 8.904 \\
\hline 0.466 & 7.762 & 16.657 & 4.985 & 10.698 & 4.557 & 9.780 \\
\hline 0.417 & 9.612 & 23.041 & 5.510 & 13.207 & 4.868 & 11.668 \\
\hline 0.391 & 12.061 & 30.853 & 6.262 & 16.017 & 5.340 & 13.660 \\
\hline 0.376 & 15.806 & 42.043 & 7.485 & 19.910 & 6.144 & 16.343 \\
\hline 0.367 & 22.379 & 60.914 & 9.713 & 26.434 & 7.645 & 20.808 \\
\hline 0.363 & 34.726 & 95.736 & 13.966 & 38.504 & 10.537 & 29.052 \\
\hline 0.360 & 61.669 & 171.255 & 23.298 & 64.699 & 16.908 & 46.954 \\
\hline 0.359 & 119.294 & 332.473 & 43.290 & 120.650 & 30.570 & 85.198 \\
\hline 0.358 & 253.370 & 707.409 & 89.823 & 250.787 & 62.377 & 174.156 \\
\hline 0.3578 & 485.778 & 1357.26 & 170.491 & 476.354 & 117.519 & 328.347 \\
\hline
\end{tabular}

\subsection{Cycle time reduction through load balancing}

The mean cycle time for various input arrival rates is already shown in table 3 . The same table is repeated in table 5, with additional columns for resource utilization of station 4 and station 12. It is clear from table 5 that station 4 and station 12 are bottleneck stations. The cycle time can be reduced drastically if additional resources are provided to stations 4 and 12 . We take only one case, where we consider only station 4 . Since station 4 is a drilling machine, adding one more machine to the facility is not a cost effective solution. Hence the alternate is to subcontract some of the jobs which enter station 4. We assume that $5 \%$ of jobs which enter station 4 for the first time are subcontracted outside, with the assumption that the service time for this $5 \%$ of job is the same as that of other jobs.

Table 5. Resource utilization of bottleneck stations.

\begin{tabular}{|c|c|c|c|}
\hline \multirow{2}{*}{$\begin{array}{l}\text { Mean IAT } \\
\text { (days) }\end{array}$} & \multirow{2}{*}{$\begin{array}{l}\text { Mean cycle } \\
\text { time (days) }\end{array}$} & \multicolumn{2}{|c|}{ Resource utilization of } \\
\hline & & Station 4 & Station 12 \\
\hline 0.901 & 4.838 & 0.3970 & 0.3348 \\
\hline 0.571 & 6.211 & 0.6262 & 0.5281 \\
\hline 0.500 & 7.075 & 0.7153 & 0.6032 \\
\hline 0.466 & 7.762 & 0.7675 & 0.6472 \\
\hline 0.417 & 9.612 & 0.8573 & 0.7229 \\
\hline 0.391 & 12.061 & 0.9148 & 0.7715 \\
\hline 0.376 & 15.806 & 0.9513 & 0.8022 \\
\hline 0.367 & 22.379 & 0.9735 & 0.8209 \\
\hline 0.363 & 34.726 & 0.9860 & 0.8315 \\
\hline 0.360 & 61.669 & 0.9932 & 0.8375 \\
\hline 0.359 & 119.294 & 0.9967 & 0.8405 \\
\hline 0.358 & 253.370 & 0.9985 & 0.8421 \\
\hline 0.3578 & 485.778 & 0.9992 & 0.8427 \\
\hline
\end{tabular}


Table 6. Cycle time reduction through load balancing.

\begin{tabular}{|c|c|c|c|c|c|c|}
\hline \multirow[b]{2}{*}{$\begin{array}{l}\text { Mean } \\
\text { IAT } \\
\text { (days) }\end{array}$} & \multicolumn{2}{|c|}{ Before load balancing } & \multicolumn{2}{|c|}{ After load balancing } & \multicolumn{2}{|c|}{ After load balancing } \\
\hline & $\begin{array}{l}\text { Cycle } \\
\text { time } \\
\text { (days) }\end{array}$ & $\begin{array}{c}\text { Resource } \\
\text { utilization } \\
\text { station } 4\end{array}$ & $\begin{array}{c}\text { Cycle time } \\
\text { (exponential } \\
\text { service } \\
\text { time) }\end{array}$ & $\begin{array}{c}\text { Resource } \\
\text { utilization } \\
\text { station } 4\end{array}$ & $\begin{array}{l}\text { Cycle time } \\
\text { (uniform } \\
\text { service } \\
\text { time) }\end{array}$ & $\begin{array}{l}\text { Cycle time } \\
\text { (det. } \\
\text { service } \\
\text { time) }\end{array}$ \\
\hline 0.901 & 4.838 & 0.3970 & 4.550 & 0.3771 & 3.995 & 3.869 \\
\hline 0.571 & 6.211 & 0.6262 & 5.721 & 0.5949 & 4.311 & 4.100 \\
\hline 0.500 & 7.075 & 0.7153 & 6.420 & 0.6795 & 4.502 & 4.210 \\
\hline 0.466 & 7.762 & 0.7675 & 6.950 & 0.7291 & 4.640 & 4.287 \\
\hline 0.417 & 9.612 & 0.8573 & 8.238 & 0.8144 & 4.993 & 4.490 \\
\hline 0.391 & 12.061 & 0.9148 & 9.588 & 0.8691 & 5.380 & 4.722 \\
\hline 0.376 & 15.806 & 0.9513 & 10.978 & 0.9038 & 5.794 & 4.980 \\
\hline 0.367 & 22.379 & 0.9735 & 12.265 & 0.9248 & 6.195 & 5.234 \\
\hline 0.363 & 34.726 & 0.9860 & 13.302 & 0.9367 & 6.521 & 5.444 \\
\hline 0.360 & 61.669 & 0.9932 & 14.061 & 0.9435 & 6.761 & 5.600 \\
\hline 0.359 & 119.294 & 0.9967 & 14.505 & 0.9469 & 6.902 & 5.692 \\
\hline 0.358 & 253.370 & 0.9985 & 14.746 & 0.9486 & 6.679 & 5.742 \\
\hline 0.3578 & 485.778 & 0.9992 & 14.846 & 0.9493 & 7.011 & 5.763 \\
\hline
\end{tabular}

Table 6 shows effect of load balancing on mean cycle time. Column 2 gives mean cycle time for the base model; column 3 is the resource utilization of station 4; column 4 gives mean cycle time with only 0.93974 of jobs from station 3 entering station 4 which is equivalent to adding additional resource to station 4. Column 5 shows utilization of station 4 after load balancing. From this table it is very clear that even 5\% less load on station 4 drastically reduces the cycle time of the system. Further reduction in cycle time is obtained by process control explained earlier, on the load balanced system.

\section{Practical implications of the results}

Experiments conducted on the queueing network model of the PCB fabrication process to reduce the fabrication cycle time reveal the following insights. By controlling the input arrival rate of new jobs, 25\% decrease in cycle time can be achieved, for a commonly observed input arrival rate of 2.5 jobs/day. This result shows that, if the variability in inter-arrival times of new jobs is minimized, the mean fabrication cycle time reduces. The message here is, accept a new order only when a job exits from the process, after completion of entire processing, thereby insuring constant population within the system. Certain amount of risk is involved here, in the sense that, one may have to reject some new orders when the system is full with its predefined number of job population, and sometimes getting a new order is difficult when a job is required to be inducted into the system. A practical way of looking at this is to intelligently schedule in-bound raw materials, chemicals, and boards from upstream vendors in such a way as to synchronize as far as possible with the departure of finished lots from the system. This calls for effective communication, constant interaction, and synergistic co-ordination with suppliers and customers.

If a well-laid out process is maintained, and followed at each station (thereby reducing the variability in service time) the overall cycle time can drop by significant amounts. We have seen that the majority of stations in the PCB fabrication process operations 
are chemical in nature. Here the variability in processing time is very low and accurate processing times are insured by well-laid down procedures. Statistical process control techniques are also useful here. The variability in service times of other human-related activities like inspection, pattern imaging, and panel cutting, will also have to be reduced to compress the cycle time. This calls for appropriate measures by the management.

For an inter-arrival time of 2.5 orders/day, the cycle time reduces to $75 \%$, if $5 \%$ of drilling jobs are subcontracted outside, thereby reducing the queueing time at the drilling station. The PCB-FAB company has already realized that CNC drilling is a bottleneck stage and the company has indeed been subcontracting a certain number of their drilling jobs to external partners.

Considering the result of the work carried out, there is enough scope for further research in the following areas. In our PCB fabrication process, we have assumed only double-sided PCB, which is the most commonly used PCB type. But fabrication of single sided PCB is also being done in the same company. Thus for accurate modelling of the PCB fabrication company PCB-FAB, it is necessary to model the fabrication process as a multi-class queueing network model. In this study, we have considered mean and variance of fabrication cycle time as our primary performance measures. The experiments carried out have only concentrated on improving cycle time performance. Other performance measures like work-in-process, throughput, and resource utilization have strong correlation to cycle time and therefore have not been explicitly considered. There are, however, other performance metrics which are important and therefore need to be looked into, such as: cost, quality, and reliability.

We have developed, analysed, and attempted to optimise the PCB fabrication process. This model is sufficiently generic and conceptual. Its scope extends beyond the PCB fabrication process. Similar modelling techniques can be used for modelling fabrication of any other product.

\section{References}

Adler P S, Mandelbaum A, Nguyen V, Schwerer E 1995 From project to process management: An empirically-based framework for analyzing product development time. Manage. Sci. 41: 458-484

Adler P S, Mandelbaum A, Nguyen V, Schwerer E 1996 Getting the most out of your product development process. Harvard Business Rev. 22: 134-152

Clark K B, Wheelwright S C 1993 Managing new product and process development (New York: Free Press)

Hopp W J, Spearman M L, Woodruff D L 1990 Practical strategies for lead time reduction. Manuf. Rev. 3: 78-84

Hopp W J, Spearman M L 1996 Factory physics: Foundations of manufacturing management (New York: Irwin)

Kiran Kumar V 1995 Queueing network models of new product development. M E Project Report, Department of Computer Science and Automation, Indian Institute of Science, Bangalore

Krishnan V, Eppinger S D, Whitney D E 1995 Accelerating product development by the exchange of preliminary product design information. J. Mech. Des. 117: 491-498

Lyons K W, Duffey M R, Anderson R C 1995 Product realization process modeling: A study of requirements, methods, and research issues. Technical Report, National Institute of Standards and Technology, Gaithersburg, Maryland, USA 
Millson M R, Raj S P, Wilemon D 1992 A Survey of major approaches for accelerating new product development. J. Product Innovation Manage. 9: 53-69

Nagaraju P 1997 Analytical and object-oriented process models for software product development. M E Project Report, Department of Computer Science and Automation, Indian Institute of Science, Bangalore

Narahari Y, Viswanadham N, Kiran Kumar V 1999 Lead time modeling and acceleration of product design and development. IEEE Trans. Robotics Autom. 15: 882-896

Suri R, Veeramani R, Church J 1995 Industry teams up with university to drive Quick Response Manufacturing. IIE Solutions 27(11): 27-30

Suri R 1998 Quick response manufacturing: A companywide approach to reducing lead times (New York: Productivity Press)

Viswanadham N, Narahari Y 1992 Performance modeling of automated manufacturing systems (Englewood Cliffs, NJ: Prentice Hall) 